\title{
ESTRUTURA FINA DO ESPERMATOZÓIDE DE TAGELUS PLEBEIUS (LIGHTFOOT) (MOLLUSCA, BIVALVIA) DO LITORAL NORTE DO BRASIL
}

\author{
Edilson Matos ${ }^{1}$ \\ Patricia Matos 2 \\ Graça Casal $^{3}$ \\ Carlos Azevedo 4
}

\begin{abstract}
FINE STRUCTURE OF THE SPERMATOZOON OF TAGEIUS PLEBEIUS (LIGHTFO-

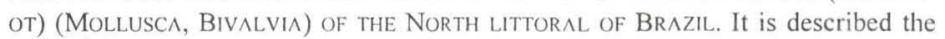
sperm ultraestructure differentiation during spermiogenesis of Tagelus plebeius (Lightfoot, 1786). The spermatozoon is an uniflagellated cell of the primitive type. The head region contains a rounded or conical nucleus surrounded by acrosome. The middle piece contains four mitochondria which are arranged around the axoneme. The flagellum contains the usual microtubular axoneme.

KEY WORDS. Mollusca, Bivalvia, Tagelus plebeius, ultrastructure, spermatozoa
\end{abstract}

Quase nada é conhecido sobre a biologia deste bivalve no Brasil. Esses animais são citados apenas em trabalhos de sistemática ou em listas de distribuição de espécies de moluscos do litoral brasileiro. A reprodução, o desenvolvimento e o ciclo sexual são pontos de vital importância na pesquisa de sua biologia, pois sem indicações seguras sobre o ritmo e ciclo reprodutivo outros aspectos biológicos seriam dificilmente compreendidos. Com respeito à maturação espermática de lamelibrânquios, observações ultraestruturais têm sido realizadas e publicadas (LONGO et al. 1969), e mais recentemente estudos concernentes a espermatogênese (DORANGE \& PENNEC 1989; ROCHA \& AZEVEDO 1990). A morfologia espermática tem sido sucessivamente examinada na filogenia de Marsupiais (HuGHES 1965) e Gastropoda FRANZÉN (1955) e tem sido sugerida uma avaliação correta para conhecimento da ultraestrutura do espermatozóide de bivalves, que possa ser usada na taxonomia proposta (POPHAM 1979; FrANZÉN 1983). A estrutura e desenvolvimento do espermatozóide da grande maioria de moluscos bivalves tem sido

1) Departamento de Biologia Animal, Histologia e Embriologia, Faculdade de Ciências Agrárias do Pará. 66077-530 Belém, Pará, Brasil.

2) Departamento de Histologia e Embriologia, Universidade Federal do Pará. 66075-900 Belém, Pará, Brasil.

3) Laboratório de Biologia Celular, Instituto Superior de Ciências da Saúde. 4580 Paredes, Portugal.

4) Departamento de Biologia Celular, Instituto de Ciências Biomédicas, Universidade do Porto. 4050 Porto, Portugal. 

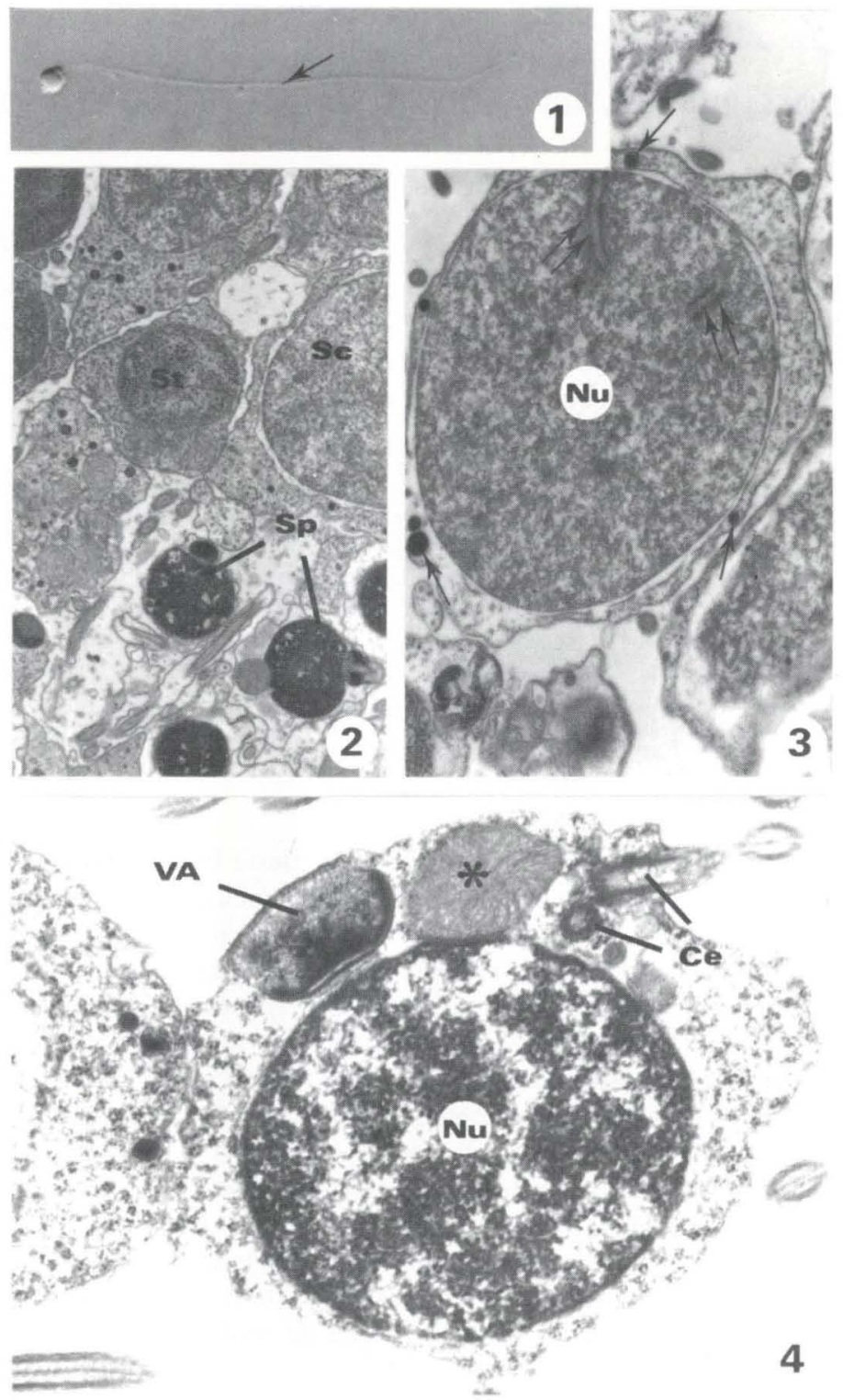

Figs 1-4. (1) Espermatozóide maduro observado em microscopia óptica de contraste de interferência - Nomarski - flagelo (setas), $10 \mu \mathrm{m}$; (2) corte ultrafino evidenciando alguns estágios da espermatogênese: espermatócito I (SC), espermatide (St) e espermatozóides (Sp), $4 \mu \mathrm{m}$; (3) núcleo (Nu) de um espermatócito I: vesículas pré-acrosômicas (seta), complexos sinaptonêmicos (dupla seta), $3 \mu \mathrm{m}$; (4) espermátide jovem: núcleo ( $\mathrm{Nu}$ ), centríolos $(\mathrm{Ce})$, vesícula acrosômica (VA) e uma mitocôndria (*), $1 \mu \mathrm{m}$. 
estudado. Os moluscos bivalves possuem um espermatozóide do tipo primitivo (FrANZÉN 1983), característica de animais com fertilização externa (POPHAM 1974).

O objetivo principal deste trabalho é o estudo do ciclo sexual de Tagelus plebeius (Lightfoot, 1786), através do estudo ultraestrutural de seu espermatozóide, durante o processo da espermatogênese.

\section{MATERIAL E MÉTODOS}

Espécimes de Tagelus plebeius foram coletados nos braços do rio Cuiarana, Salinópolis, Pará $\left(00^{\circ} 36^{\prime} 47^{\prime \prime} \mathrm{S}, 47^{\circ} 21^{\prime} 30^{\prime \prime} \mathrm{W}\right)$ durante o período anual em que se processa o amadurecimento gonadal. Pequenos fragmentos de testículos foram fixados em glutaraldeído a 2,5\% mais uma gota de acetato de uranila a $5 \%$ em tampão cacodilato de sódio $0,2 \mathrm{M} \mathrm{e} \mathrm{pH} 7,4$ a $4^{\circ} \mathrm{C}$ durante duas horas.

Após lavagem no mesmo tampão durante duas horas a $4^{\circ} \mathrm{C}$, os fragmentos foram pós-fixados em tetróxido de ósmio a $2 \%$ no mesmo tampão, a $4^{\circ} \mathrm{C}$ durante duas horas. O tecido foi então desidratado em série crescente de álcool etílico, seguido de três trocas de óxido de propileno. A inclusão foi feita em Epon, os cortes semifinos e ultrafinos em ultramicrótomo com faca de vidro e diamante, e a dupla contrastação com solução aquosa saturada de acetato de uranila e citrato de chumbo MATOS et al. (1995). As grades contendo os cortes foram examinadas, e estes fotografados em miscroscópio eletrônico JEOL 100CXII, operando a $60 \mathrm{Kv}$.

\section{RESULTADOS}

O espermatozóide de Tagelus plebeius está dividido em três partes: a cabeça, constituída por núcleo e acrosoma; peça intermediária formada por dois centríolos e mitocôndrias; e cauda (Fig. 1).

Durante o processo evolutivo espermático foi possível observar espermatozóides em diferentes estágios de desenvolvimento (Fig. 2), assim como espermatócitos I em estado de zigóteno/paquíteno, apresentando complexos sinaptonêmicos e vesículas pré-acrosômicas (Fig. 3). Durante a fase inicial de desenvolvimento da espermátide o núcleo apresenta uma forma esférica com reduzido grau de compactação da cromatina. A vesícula acrosômica diferencia-se, no entanto, sem uma posição definida (Fig. 4). Posteriormente, a vesícula acrosômica desloca-se para a região anterior, diferenciando-se no seu interior duas zonas com diferentes eletrodensidades. Simultaneamente as mitocôndrias e os centríolos colocam-se numa posição oposta (Fig. 5). Na fase final de desenvolvimento do espermatozóide a cromatina apresenta um grau máximo de compactação. Na vesícula acrosômica, diferencia-se um feixe de microfilamentos designado de perfuratório (Fig. 7) e na peça intermediária as quatro mitocôndrias envolvem o centríolo distal que entretanto, origina o flagelo (Fig. 6). 

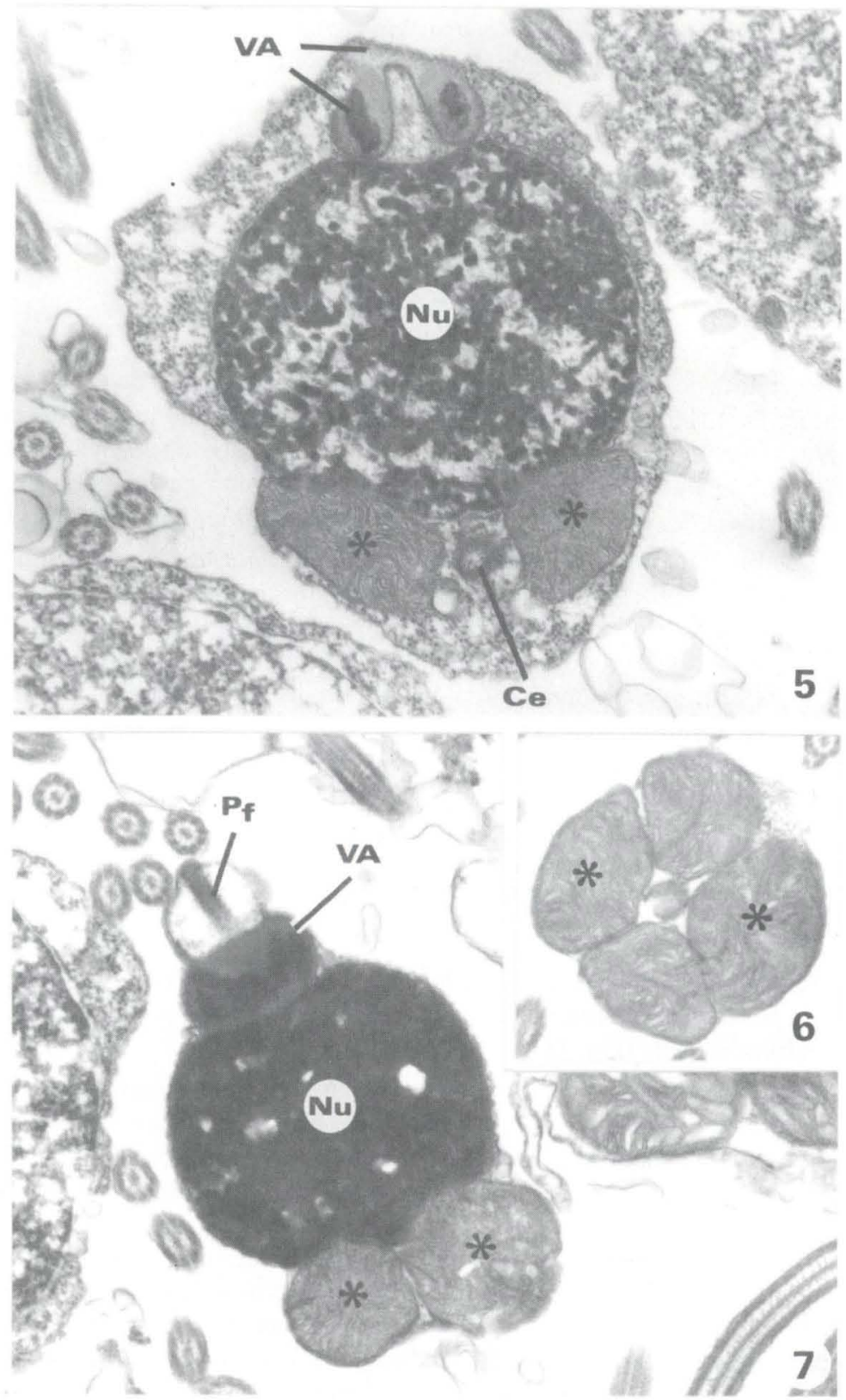

Figs 5-7. (5) Espermátide em fase adiantada de desenvolvimento evidenciando no núcleo (Nu) a condensação da cromatina, vesicula acrosômica (VA), mitocôndrias ( $\left(^{\star}\right)$ e centríolo (Ce); (6) peça intermediária constituída por quatro mitocôndrias (*); (7) espermatozóide maduro: núcleo (Nu), vesícula acrosômica (VA), perfuratório (Pf) e mitocôndrias (*). Todas com $1 \mu \mathrm{m}$ 


\section{DISCUSSÃO}

Os resultados da espermatogênese do presente estudo, aliado a estudos prévios descritos por REUNOV \& DROzDOv (1987), SousA et al. (1989) e RochA \& AZEVEDO (1990) têm mostrado que o flagelo e a vesícula pró-acrosomal estão presentes nas células durante o processo espermiogênico em algumas famílias de moluscos bivalves, tendo sido constatada também em Tagelus plebeius. Em algumas espécies, o flagelo de cada espermatogônia e espermatócito são absorvidos durante a pró-metáfase (KATO \& ISHIKAWA 1982; ISHIKAWA et al. 1986), mas pode ocorrer a retenção do flagelo durante a divisão celular, segundo PAULUS (1989). O desenvolvimento flagelar em espermatogônias e espermatócitos, não é exclusivo dos moluscos bivalves, uma vez que pode ocorrer em esponjiários (PAULus 1989), cnidários (DEWEL \& CLARK 1972) e equinodermos (KATO \& ISHIKAWA 1982). O significado da presença do flagelo nas células pré-espermiogênicas, ainda é obscuro, e a organização descrita neste estudo é comum em outros bivalves, assim como em outras espécies de invertebrados.

AGRADECIMENTOS. Ao Prof. Dr. Osmar Domaneschi (Instituto de Biociências, Universidade de São Paulo) pela identificação da espécie. Ao Sr João Carvalheiro pelo serviço iconográfico. Trabalho parcialmente subsidiado pela Universidade do Porto/Portugal, FCAP, UFPa, CEPNOR/IBAMA, e Fundação Engenheiro António de Almeida (Portugal).

\section{REFERÊNCIAS BIBLIOGRÁFICAS}

DEWEL, W.C. \& W.H. CLARK. 1972. An ultrastructural investigation of spermiogenesis and the mature sperm in the anthozoan Bunodosoma cavernata (Cnidaria). Jour. Ultrastruct. Res. 40: 417-431.

DoRANGE, G. \& M. LE PENNEC. 1989. Ultrastructural characteristics of spermatogenesis in Pecten maximus (Mollusca, Bivalvia). Invert. Reprod. Dev. 15: 109-117.

FRANZÉN, A. 1955. Comparative morphological investigations into spermiogenesis among Mollusca. Zool. Bidr. Upps. 30: 399-456.

1983. Ultrastructural studies of spermatozoa in three bivalves species with notes on evolution of elongated sperm nucleus in primitive spermatozoa. Gamete Res. 7: 199-214.

HugHeS, R.L. 1965. Comparative morphology of spermatozoa from five marsupial families. Aust. Jour. Zool. 13: 533-543.

ISHIKAwA, M.; G.P. VERMA; K.H. KATO \& M. IRIE. 1986. Centriolar behavior and flagellum formation during spermatogenesis in the sea urchin in vivo and in vitro. In: M. Porchet, J.C. Andries \& A. Dhainaut (Eds). Advances in Invertebrate Reproduction. Amsterdam, Elsevier, 522p.

KATO, K.H. \& M. ISHIKAWA. 1982. Flagellum formation and centriolar behavior during spermatogenesis of the sea urchin, Hemicentrotus pulcherrimus. Acta Embryol. Morphol. Exp. 3: 49-66.

LONGO, F.J. \& E. ANDERSON. 1969. Sperm differentiation in the sea urchin Arbacia 
punctata and Strongylocentrotus purpuratus. Jour. Ultrastruct. Res. 27: 486509.

Matos, E.; P. MAtos; L. Corral \& C. Azevedo. 1995. Estudo ultraestrutural da espermatogenese de Donax striatus Linnaeus (Mollusca, Bivalvia) do litoral norte do Brasil. Revta bras. Zool. 12: 221-227.

PAULUS, W. 1989. Ultrastructural investigation of spermatogenesis in Spongilla lacustris and Ephydatia fluviatilis (Porifera, Spongillidae). Zoomorphology 109: 123-130.

POPHAM, J.D. 1974. Comparative morphometrics of the acrosomes of the sperms of "externally" and "internally" fertilizing sperms of the shipworms (Teredinidae,Bivalvia,Mollusca). Cell Tissue Res. 150: 291-297.

. 1979. Comparative spermatozoon morphology and bivalve phylogeny. Malacol. Rev. 12: 1-20.

Reunov, A.A. \& A.L. Drozdov. 1987. Spermatogenesis and ultrastructure of spermatozoa of the mussel Mytilus coruscus. Tsitologia 29: 260-266.

RocHA, E. \& C. AzEVEDO. 1990. Ultrastructural study of the spermatogenesis of Anodonta cygnea L. (Bivalvia, Unionidae). Invert. Reprod. Dev. 18: 169-176.

SousA, M.; L. Corral \& C. AzEvedo. 1989. Ultrastructural and cytochemical study of spermatogenesis in Scorbicularia plana (Mollusca, Bivalvia). Gamete Res. 24: 393-401.

Recebido em 04.VII.1996; aceito em 04.IX.1997. 